\title{
The global pandemic: COVID- 19
}

\author{
Meera $\mathbf{J}^{1}$, Kamal $\mathbf{M}^{2 *}$ \\ ${ }^{1}$ Consultant, ${ }^{2}$ Post Graduate Clinical Fellow, ${ }^{1}$ Dept. of Obstetrics Gynaecology Reproductive Medicine, ${ }^{2}$ Dept. of Pediatric \\ Cardiology, and, ${ }^{1}$ Fehmi Care Hospital, Hyderabad, ${ }^{2}$ Star Hospitals, Hyderabad, Telangana, India
}

*Corresponding Author: Kamal M

Email: murtaza.vmmc@gmail.com

\begin{abstract}
COVID-19, the novel corona virus disease is spreading at a rapid rate across the globe. World health organisation has declared this disease a "pandemic." A lot is still unknown about this virus till date and we all are learning about it as more and more cases are being involved. This article is being written to discuss about its epidemiology including the modes of transmission, clinical features, diagnostic modalities and its treatment with preventive measures.
\end{abstract}

Keywords: COVID-19, Corona virus, WHO, Pandemic, Pneumonia.

\section{Disclaimer}

As COVID-19 is a disease which we are encountering for the first time, we have very meager knowledge and experience about the disease and its management aspects. Literature are coming in this field from different parts of the globe. The article is being written with the present knowledge and literature which we have till date. With more experience with this disease we will be able to handle it in a much better and efficient manner.

Corona virus encompasses a large family of viruses which infect humans and animals including cattle, camels, cats and bats. Till date seven different strains of the virus have been identified which include alpha corona virus (229E and NL63), beta corona virus (OC43 and HKU1), MERS- CoV (beta coronavirus which caused middle east respiratory syndrome of 2012, or MERS), SARS- CoV (beta coronavirus that caused severe acute respiratory syndrome of 2003, or SARS) and SARS-CoV-2 (novel corona virus that causes COVID-19 of 2019-20). ${ }^{1}$

Wuhan, a city in Hubei province of China was the place in which novel corona virus was identified as a cause of respiratory tract infection both upper and lower in December 2019. Within no time it became an epidemic in China and then engulfed the whole of globe gradually in pandemic fashion. Till date 200 countries have been involved with the disease. WHO designated this disease as COVID-19, which stands for coronavirus disease $2019 .^{2}$

With respect to the mode of transmission, initially it was thought that the virus originated from snakes and later had more similarity with bats. With time as the outbreak progressed, the primary mode of transmission was recognised as person to person through droplets and fomites. When an infected person coughs, sneezes or talks, the virus is released in the respiratory secretions, which can infect others if these secretions make direct contact with the mucous membranes. The person can also be infected by touching an infected surface and then subsequently touching their eyes, nose or mouth. Patients are most contagious when they are having symptoms. ${ }^{3}$ Even neonates have not been spared of this infection with reports coming from China and London. It is unclear if the disease was transmitted in utero or after birth. ${ }^{4,5}$

Till date more than 4, 50,000 cases have been reported from various parts of the world from 200 countries. China has reported the maximum number of cases which is over 80,000 followed by Italy, USA, Spain, Germany and Iran down the lane. The rate of rise of new cases outside China has outpaced China itself making it a pandemic. India has also reported more than 600 cases till now. Globally around twenty thousand mortality has been reported by WHO.

The incubation period has been presumed to be varying from 2- 14 days with most cases occurring within 5 days post exposure. ${ }^{6-8}$ In more than four fifth of the cases infections are found to be self-limiting. Those with underlying comorbidities and above 60 years are known to have severe infections mostly. Severe illness with signs and symptoms like dyspnea, tachypnea (respiratory rate of 30/minute or above), hypoxemia, i.e. Spo $2<94 \%$, more than half of the lung involvement on imaging within initial 48 hours has been reported in about $15 \%$ cases. Critical disease with respiratory failure, shock, multi organ dysfunction syndrome is seen in just $5 \%$ of the cases. Case fatality rate ranges between 2.3 to $5 \%$. Middle aged ( $>30$ years) and elderly are the groups which are 
mostly affected. The most common symptom is pyrexia (88\%) followed by dry cough $(67 \%)$, fatigue (38\%), dyspnea (18.7\%) and myalgia (14.9\%) [9]. Pneumonia is the most severe manifestation of infection with acute respiratory distress syndrome (ARDS) in approximately 3\% of the cases. Sore throat, rhinorrhoea, headache and gastro-intestinal symptoms are other manifestations.
Chidden generally report with milder symptoms. ${ }^{10}$ Patients of the paediatric age group are relatively fewer in number $(2.4 \%)$ with milder symptoms and better prognosis. ${ }^{11}$ The mechanism for the relatively lesser number of cases in this age group has been attributed to the immaturity of the ACE2 receptors in children which has been hypothesised to be the route of entry of the virus into the cells.

\section{Table 1}

\begin{tabular}{|l|l|}
\hline Suspected case & $\begin{array}{l}\text { A patient with acute respiratory tract infection and with no other cause that fully } \\
\text { explains the clinical presentation and a history of travel or residence in an area/ country } \\
\text { reporting local/ community transmission during the } 14 \text { days prior to symptom onset or } \\
\text { A patient with any acute respiratory illness and have been in close contact with a } \\
\text { confirmed or probable COVID-19 case in the last } 14 \text { days prior to symptom onset or } \\
\text { A patient with severe acute respiratory infection (fever and at least one sign/ symptom } \\
\text { of respiratory disease) and requiring hospitalisation and no other cause that fully } \\
\text { explains the clinical presentation }\end{array}$ \\
\hline Probable case & $\begin{array}{l}\text { A suspected case for which testing for virus causing COVID-19 is inconclusive } \\
\text { (laboratory reports) or for whom testing was positive on a pan- coronavirus assey }\end{array}$ \\
\hline case & $\begin{array}{l}\text { Person with lab confirmation of COVID-19 viral infection, irrespective of signs and } \\
\text { symptoms }\end{array}$ \\
\hline Close contact & $\begin{array}{l}\text { Close contact of a probable/ confirmed case are: } \\
\text { A person living in the same household as a COVID-19 case } \\
\text { - A person having had direct physical contact with a COVID-19 case (eg: hand } \\
\text { shake) } \\
\text { A person having unprotected direct contact with infectious secretions of a COVID- } \\
\text { 19 case ( eg: coughed on) } \\
\text { A person having had face to face contact with a COVID-19 case within 2 meters } \\
\text { and }>15 \text { minutes } \\
\text { A person who was in a closed environment like meeting room/ classroom/ hospital } \\
\text { waiting room with a COVID-19 case for 15 minutes or more and a distance of less } \\
\text { than } 2 \text { meters } \\
\text { A healthcare worker/ person providing direct care for COVID-19 case or laboratory } \\
\text { workers handling specimens from a COVID-19 case without recommended } \\
\text { personal protective equipment (PPE) or a breath of PPE } \\
\text { A contact in an aircraft sitting within } 2 \text { seats in any direction of the COVID-19 } \\
\text { case, travel companions or persons providing care, and crew members serving in } \\
\text { the section of the aircraft where the index case was seated (if severity of symptoms } \\
\text { or movement of the case indicate more extensive exposure, passengers seated in the } \\
\text { entire section or all passengers on the aircraft may be considered close contacts) }\end{array}$ \\
\hline
\end{tabular}

WHO has defined clear case definition of a suspected case, probable case, confirmed case and close contact. $^{11}$

With respect to laboratory tests leucocyte count can vary, and upto $80 \%$ of the patients having leucopenia. Mild thrombocytopenia has also been observed which is considered as a poor prognostic marker. Procalcitonin have been found to be raised in patients requiring ICU care. C- reactive protein (CRP) seems to track with disease severity and prognosis. ${ }^{7}$
Respiratory specimen collection is to be performed from the upper (nasopharyngeal and oropharyngeal) and lower respiratory tract under strict airborne infection control precautions. ${ }^{12}$ All specimen collection should be done in negative pressure rooms. RT-PCR (Reverse Transcriptase Polymerase Chain Reaction) is the method of detection of SARS-CoV-2 RNA. Results are generally available within 48 hours. COVID-19 Rapid Test qualitatively detects IgG and IgM antibodies to SARS-CoV-2 in human whole 
blood, serum and plasma samples, which applies lateral flow immuno- chromatography, but there is no definitive evidence regarding its utility.

Radiologically, chest X-Ray findings are non specific in the initial few days of symptoms and can be normal too. They can show lobar, multilobar or bilateral lung consolidation. ${ }^{13}$ Computed tomographic scan (CT) can show ground glass opacity with subpleural distribution and involving predominantly the lower lobes and consolidation of the lung fields. ${ }^{14}$

As of now, the therapeutic strategies to deal with infection are only supportive and preventive; preventive strategies aim at reducing transmission in the community (the best available weapon). Isolation of (a) the individual who have tested positive for SARS-CoV-2 or (b) anyone with symptoms of fever and respiratory illness with history of close contact to a COVID-19 positive person or has a history of travel to a COVID affected region within last 14 days or (c) any health care worker with symptoms of fever and respiratory distress who has been involved directly in treating COVID-19 patients, or has close contact with persons involved in treating COVID-19 patients during the past 14 days, is strongly recommended. Asymptomatic cases with exposure to COVID-19 positive patients can be quarantined at their homes but under strict surveillance by government authorities. Signs are to be put on the main entrance indicating that the space is an isolation area. Personal protective equipment (PPE) are to be used strictly by persons and health care workers taking care of these patients. Patients need to be kept in isolation till respiratory samples are negative.

There is no specific antiviral treatment recommended for COVID-19 and no vaccine is available till date. Isolation is to be considered in asymptomatic disease. Those with severe disease ( respiratory rate $>30 / \mathrm{min}, \mathrm{Spo} 2<94 \%$, Pao2/ Fio2< 300 , lung infiltrates $>50 \%$ within 24-48 hours) and critically ill (respiratory failure, septic shock, multi organ dysfunction) need admission and intensive care support. Supportive care with oxygen, conservative fluid management, empirical antibiotics (according to institution based guidelines) and anti virals are to be started. Multiple randomised controlled trials are going on for the best anti- viral for the condition. Antivirals under trial are remdesivir (premature termination of viral RNA transcription), lopinavir/ ritonavir (CYP3A4 inhibitor), ribacvarin (RNA polymerisation inhibitor) and oseltamivir (neuraminidase enzyme inhibitor in influenza).

Off late there is a lot of interest in the potential role of ACE-inhibitors/ ARBs in the pathophysiology of the disease since this virus binds to the ACE2 receptor for cellular immunity. Theoretically it can be blocked by ARBs. Presently these is no data to support either starting or stopping ACE inhibitors/ ARBs in these patients. Interferons are known to impair the antiviral adaptive Type1 Thelper cells, but in vitro effects haven't been fully shown to be working. Chloroquine/ Hydroxychloroquine, the age old antimalarial is finding its way to a large extent. It is known to hamper the low $\mathrm{pH}$ dependent steps of viral replication. It has been even proposed for prophylaxis in some countries, although it lacks evidence. QT prolongation is a known side effect of this drug. Some centres have tried ascorbic acid too. Even this does not have any high quality evidence to support its role in viral pneumonia. Some other drugs which are under trial are favilavir, galidesivir, brilacidin, combination of monoclonal antibodies and umifenovir. The best treatment is still being hunted.

So, COVID-19 is a pandemic which has shown us its roaring face and we need to fight in a collective manner so that our beautiful earth is no more under threat.

\section{Source of funding}

None.

\section{Conflict of interest}

None.

\section{References}

1. National Center for Immunization and Respiratory Diseases (NCIRD), Division of viral diseases.

2. World Health Organisation (WHO). Director General's remarks at the media briefing on 2019-nCoV on 11 February 2020.

3. Li Z, Yi Y, Luo X. Development and clinical application of a rapid IgM-IgG combined antibody test for SARS-CoV-2 infection diagnosis. J Med Virol 2020.

4. https://www.bbc.com/news/world-asia-china-51395655

5. https://nypost.com/2020/03/13/second newborn baby tests positive for coronavirus/

6. Li q, Guan X, Wu P. Early transmission dynamics in Wuhan, China of novel corona virus infected pneumonia. $N$ Engl J Med 2020.

7. Guan WJ, Ni ZY, Hu Y. Clinical characteristic of corona virus disease 2019 in China. N Eng J Med 2020.

8. Chan JF, Yuan S, Kok KH. A familial cluster of pneumonia associated with the 2019 novel corona virus indicating person to person transmission: a study of a family cluster. Lancet 2020;395:514.

9. Wei M, Yuan J, Liu Y, Fu T, Yu X, Zhang ZJ et al. Novel corona virus infection in hospitalised infants under one year of age in China. JAMA 2020. Don: 10.1001/jama.2020.2131. [Epub ahed of print].

10. W Guan, Z Ni, Yu Hu, W Liang, C Ou, J He, et al. Clinical characteristics of coronavirus disease 2019 in China. 
11. https:// www.who.int/docs/default-source/ corona virus/ who-china-joint-mission-on-covid-19-final-report.pdf.

12. https://www.ecdc.europa.eu/en/case-definition-and -europe an-surveillance-human-infection-novel-coronavirus-2019ncov

13. Kanne JP, Little BP, Chung JH, Elicker BM, Ketai LH. Essentials for Radiologists on COVID-19: An UpdateRadiology Scientific Expert Panel. Radiology

[Internet].2020;200527. Available from: http: www. ncbi. nlm. nih.gov/pubmed/32105562.

14. Pan Fen Ye, Tianhe Sun, Peng Gui, Shan Liang, Bo Li, Lingli Zheng, et al. Time Course of Lung Changes On
Chest CT During Recovery From 2019 Novel Coronavirus (COVID-19) Pneumonia. Radiol 2020;77(8):1-15.

How to cite: Meera J, Kamal M, The global pandemic: COVID- 19. IP Int J Med Paediatr Oncol 2020;6(1):10-3. 